\section{Tools and technologies}

Building a biopharma-focused company based on a technology or service presents unique challenges. This month, we feature two people who have successfully tackled these challenges: one in the field of genetic engineering, and one in the field of chemical libraries.

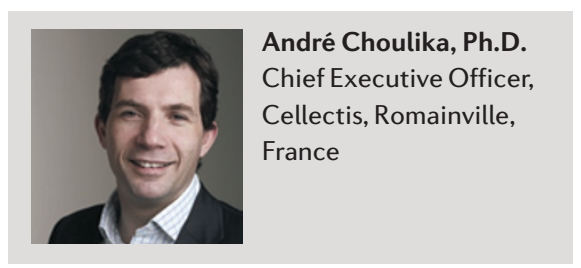

The sequencing of the human genome provided a catalyst for the creation of numerous technology companies, although many have disappeared or changed business model since the funding environment for such companies became much more challenging. Cellectis, however, which is based on a technology for tailored genome engineering, has continued to grow since its foundation in 2000 while maintaining its original focus. "I'm amazed at how far we've come in 7 years," says CEO André Choulika. "On the scientific level, I feel our technology is unmatched, and on the financial level, we've experienced significant growth in our valuation, and we are not yet at the full potential of our business."

Choulika co-founded Cellectis with David Sourdive, a fellow scientist at the Institut Pasteur in Paris, with the aim of exploiting the potential of a class of nucleases known as meganucleases, specifically cut a unique DNA target site in vivo, thereby allowing genome engineering. "I moved from academic research into the world of business because I needed to give free rein to my creativity, not only in the biological sciences but also with the dream of starting a company," recalls Choulika.

Spending time in the United States was a major catalyst in realizing this dream, feels Choulika, who decided to leave the Institut Pasteur after his Ph.D. to pursue a postdoc in Richard Mulligan's lab at Harvard Medical School in Boston. "It was a great experience and unleashed my thirst to live an adventure that went beyond pure academic research," he says. "It also opened my eyes to the dynamic interchange between academic research and the private sector that is there in the USA - something I hadn't found in France. The adventure that is entrepreneurship and starting up a business was a natural choice." This motivation for the adventure of entrepreneurship has been important in bringing Cellectis to its current point, with which can be designed to recognize and

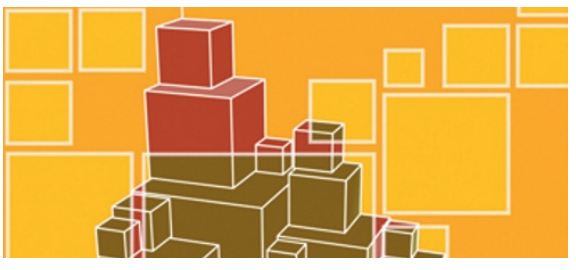

45 employees and 14 products in development, given the well-known funding difficulties that technology-based companies experienced following the bursting of the biotech bubble. "Communicating and sharing our enthusiasm and convincing our shareholders to endorse our vision has sometimes been challenging," says Choulika. "It was particularly difficult when we were in a purely research phase. Results take time to surface and to be validated, and too much pressure on scientists can lead you in the wrong direction and into trouble. So, you have to share your successes and your failures with honesty and clarity."

Now, the scientific results of the company have been translated into commercial agreements that have confirmed its business model - something that Choulika has found particularly rewarding, and which is reflected in the advice he would give to other potential entrepreneurs. "When you think you have a good business model, stick with it and believe in yourself. Perseverance, enthusiasm and belief in what you're doing are the ingredients needed to accomplish your goals and to enjoy the experience."

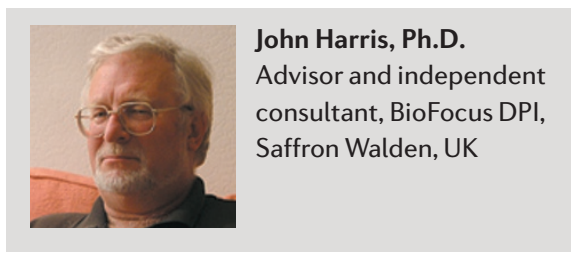

A surge in the number of potential drug targets arising from genomics in the 1990 s created a demand for technologies that could help in exploiting this potential. However, translating this demand into a sustainable business was a major challenge. "BioFocus DPI [now a division of Galapagos NV (Belgium)], is a very rare example of a profitable collaborative drug discovery operation providing services and molecules to the global pharma and biotech industries," says John Harris, who co-founded BioFocus in 1997.

Harris started his industrial career in 1974 at Wellcome Laboratories, Beckenham, UK, as a medicinal chemist working with Sir John Vane on prostaglandin analogues, and contributed to a number of clinical candidates, including one of the first wholly synthetic prostaglandin drugs. During his two decades at Wellcome, he rose to become the head of cardiovascular research in the UK, and then developed and led the first 'combichem' discovery unit within Wellcome in the early 1990s.

Motivated in part by a desire to have greater control over the science he was doing, Harris cofounded BioFocus with six colleagues, including three from what was then GlaxoWellcome following the 1994 merger with Glaxo. "We perceived an increasing need at the time for the post-MEA pharma industry to outsource their research as well as their development — and we were proved right!" says Harris.

Nevertheless, raising the initial funding was very difficult, especially as a service-orientated company was not then attractive for venture funding. "In the end, we founded the company on capital raised in the public OFEX market, which, as far as we know, is a unique start to a biotech start-up," says Harris. "This was risky, as we could have ended up with nothing if we hadn't met our profit targets, but fortunately, we did."

From 1997, as Chief Scientific Officer, Harris established the science and technology base of the company. "Our initial aim was to provide compounds and reagents based on combinatorial chemistry," recalls Harris. "But we found that there was a demand for our medicinal chemistry expertise. In particular, some of the more forwardlooking companies at the time were coming to us asking for compound libraries focused on particular target classes, such as kinases." Recognizing the potential wide demand for such libraries, BioFocus built them using combichem techniques, and marketed them non-exclusively. Their focused library design technology, known as SoftFocus, has been one of the main revenue generators for the company, with over 100 clients.

Following his retirement from the full-time CSO post, Harris has recently taken on a role as an independent consultant to BioFocus DPI. "What I aim to do is to keep the company in 'innovation mode'- my own experiences will help to ensure that BioFocus DPI does not repeat the mistakes other energetic young companies have made as they have grown," says Harris. "Size and quality in science do not go together well - in fact, often they go in opposite directions. Retaining the intimacy, energy and freedom of thought that distinguishes small biotech/pharma from many big players and enables them to keep innovating, whilst keeping excessive bureaucracy at bay, is not at all easy." 